\title{
La memoria histórica en los institutos, una aproximación al patrimonio histórico educativo
}

\begin{abstract}
Las visitas que recientemente ha realizado el IAPH a dos instituciones de enseñanza en Granada y Sevilla (IES Padre Suárez e IES San Isidoro respectivamente) para la formulación de sendos estudios técnicos sobre el estado de conservación de sus fondos, han llamado poderosamente nuestra atención y nos invitan a una reflexión sobre el llamado patrimonio histórico educativo, su origen, trayectoria y los agentes implicados en su conservación y puesta en valor.
\end{abstract}

María Campoy Naranjo | Centro de Intervención del IAPH

URL de la contribución <www.iaph.es/revistaph/index.php/revistaph/article/view/3382>

Si ya es sorprendente que estas instituciones conserven entre sus fondos colecciones bibliográficas de incuestionable valor histórico, más llamativo resulta que la falta de uso del material didáctico y científico, por antiguo y obsoleto, haya propiciado potentes iniciativas por parte de la dirección docente encaminadas a su conservación y difusión. Desde aquí felicitar el esfuerzo anónimo de la comunidad educativa que, con escasos medios, está implicando a los colectivos sociales en la preservación de su legado educativo.

La ampliación del concepto de patrimonio a ámbitos donde la principal baza no siempre es el interés histórico ha contribuido a la puesta en valor de los llamados patrimonios emergentes. Su influencia no ha pasado desapercibida en la órbita de la educación, quizá por la generalización de la escolarización a todos los estratos de nuestra sociedad, constituyendo lo que se viene a denominar patrimonio histórico educativo.

Testigo del devenir de la educación en los últimos 150 años y uno de los más ricos patrimonios colectivos de este país, dos vienen a ser sus principales rasgos: la compleja diversidad de los fondos que lo integran y la estrecha relación con su entorno y su necesaria contextualización.

Creados y puestos al servicio de la enseñanza con la Ley Moyano de 1857, forma parte del patrimonio educativo tanto los espacios y edificios (la biblioteca, los entonces gabinetes de historia natural, jardines botánicos y labo- ratorios) como los objetos didácticos (libros y manuales, mobiliario, enseres, material didáctico y científico) y los generados por el propio medio escolar (expedientes, diplomas, exámenes, trabajos manuales, fotografías, cuadernos escolares, etc.). El conjunto constituye una herencia material de valores incuestionables como documento del paso del tiempo.

A diferencia del patrimonio artístico, no son objetos valiosos en el mercado y suelen contar con una elaboración sencilla y material pobre. Pero ello no debe llevarnos a engaño. Su mayor potencial radica en su capacidad para evocar en el individuo sentimientos y recuerdos ligados a nuestra infancia y juventud, a nuestras primeras experiencias. A este incuestionable valor inmaterial se suman otros rasgos ligados a las tradiciones y expresiones orales, las prácticas, rituales y festividades y la evolución de la propia enseñanza (canciones, juegos, adivinanzas, el saludo al maestro, las filas de alumnos, los disfraces, las fiestas del fin de curso, etc.).

El origen del patrimonio educativo, aunque no exclusivo, teniendo en cuenta la convulsa historia reciente española que derivó en modelos educativo dispares, debe buscarse en los institutos históricos creados al amparo de la Ley Pidal (1841) durante los años centrales del siglo XIX y todo el primer tercio del XX.

Tal vez ello explique que en su salvaguarda haya jugado un papel decisivo el colectivo docente adscrito a la ense- 


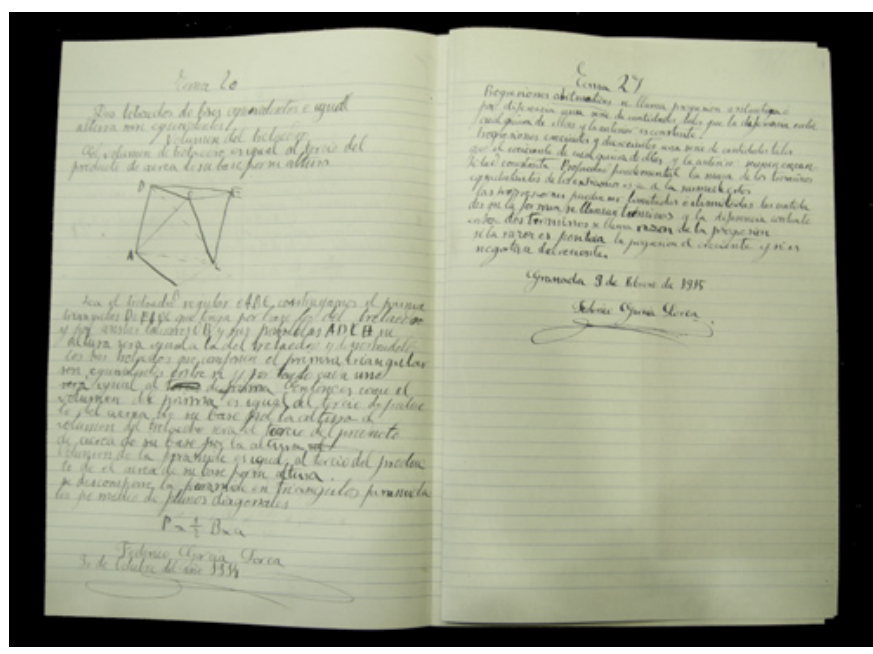

Dos exámenes realizados por Federico García Lorca, antiguo alumno del Instituto Padre Suárez de Granada, escritos a pluma y fechados en 1914 y 1915 | foto IES Padre Suárez (Gilberto González)

ñanza secundaria. Por su proximidad y conciencia sobre el peligro de su pérdida y desaparición, puso las bases de un movimiento que, aunque iniciado tímidamente a finales de 2006, ha dado un paso gigante en la localización y catalogación de sus bienes. La Asociación Nacional en Defensa del Patrimonio de los Institutos Históricos (ANDPIH), constituida oficialmente en julio de 2010, celebra desde 2007 jornadas anuales que han conformado una red de centros con patrimonio histórico educativo cuyo bagaje muestra la diversidad de sus tesoros, lo que ha suscitado un creciente interés entre los especialistas materializándose en infinidad de estudios, investigaciones, congresos, exposiciones y museos.

La casi totalidad de estos institutos y escuelas se ubican en antiguos edificios conventuales procedentes de la desamortización eclesiástica y resultan claramente identificables por su morfología monumental, constituyendo en sí mismos los "contenedores" que, con mayor o menor fortuna, han conservado hasta hoy el patrimonio educativo.

Paradójicamente, iniciativas para su protección desde instancias ajenas ligadas a la administración y la universidad ponen en riesgo la contextualización de dicho patrimonio, cuyo hábitat natural no debe ser otro que el propio instituto. Como ejemplos, los museos pedagó- gicos de creación oficial surgidos a fines de la pasada década de los ochenta en Huesca y Albacete y los que, a iniciativa del profesorado, están surgiendo en el nuevo siglo en los propios centros de enseñanza (IES Aguilar y Eslava en Cabra -Córdoba-, IES Cabrera Pinto en La Laguna, o en el mencionado Padre Suárez en Granada). Estas colecciones contrastan con el desafortunado caso de los fondos del IES San Isidro de Madrid que, por la falta de espacio, se destinó al Museo de Ciencia y Tecnología y hoy día buena parte de su colección permanece oculta, y la que está expuesta se encuentra desvinculada de su entorno.

Sin duda, la iniciativa del colectivo docente ha constituido el germen para que las instancias académicas y políticas lleven un lustro prestando atención en nuestro país al patrimonio histórico educativo. Como ejemplos, el Consejo Escolar del Estado publica con periodicidad cuatrimestral la revista Participación Educativa, cuyo séptimo número (marzo, 2008) se dedicó al patrimonio de los institutos históricos; desde entonces reserva una sección para este legado. También la Dirección General de Investigación de la Consejería de Educación de la Comunidad de Madrid puso en marcha en 2008 el Programa I+D CEIMES para la salvaguarda y revalorización del patrimonio cultural de los institutos de bachillerato más antiguos de Madrid (1837-1936).

Estas iniciativas llegaron al Congreso de los Diputados, aprobándose el 24 de marzo de 2009 la Proposición no de Ley en apoyo a los institutos históricos, creando un plan de protección, conservación y difusión del patrimonio educativo que debe contemplar la elaboración de inventarios y catálogos de bienes, medidas para la preservación de las colecciones, estrategias para el mantenimiento de los edificios escolares históricos, la investigación y divulgación de dicho patrimonio y créditos presupuestarios para la ejecución del mencionado plan.

El Ministerio de Educación abrió entonces una línea de actuación a través del Programa ARCE (2009-2013) con vistas a la recuperación y uso didáctico de las colecciones, conservación y catalogación. Paralelamente se llevó a cabo un programa de formación en materia de 


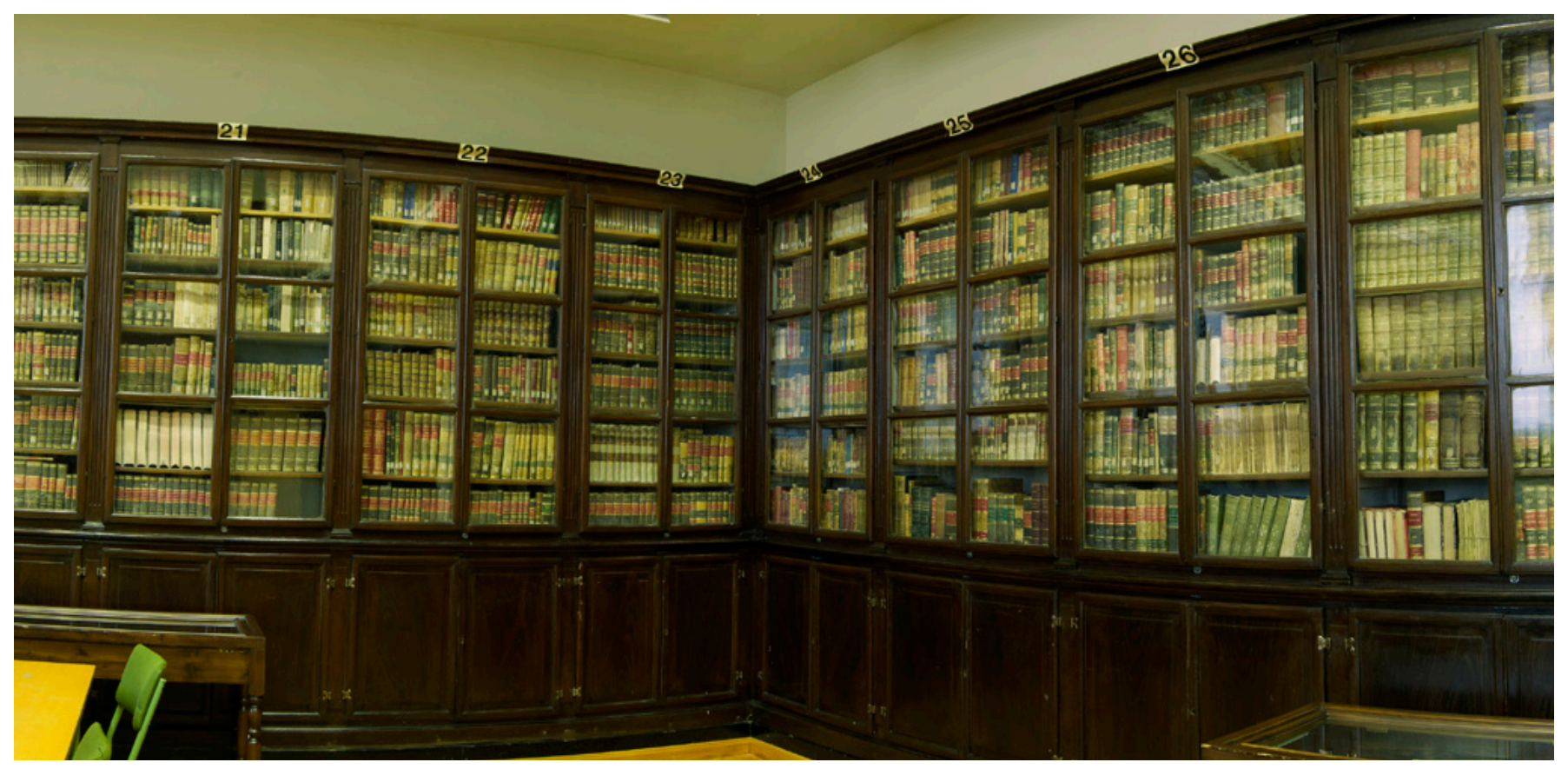

Biblioteca del Instituto Padre Suárez de Granada | foto IES Padre Suárez (Gilberto González)

conservación del patrimonio documental y bibliográfico en la Biblioteca Nacional y para el mantenimiento de colecciones de historia natural y científicas en el Museo Nacional de Ciencias Naturales impartido a un centenar de docentes. El proyecto contempla también la difusión en la red de las bibliotecas escolares.

Estas actividades culminaron en las primeras Jornadas sobre Patrimonio Histórico Educativo celebradas en Granada en noviembre de 2011 bajo el auspicio del Ministerio de Educación y el Consejo Escolar del Estado, en las que se trazó el futuro del patrimonio histórico educativo y la definición de las nuevas estrategias para el mayor alcance a la sociedad.

Pero todavía hoy, el patrimonio histórico educativo es un compañero desconocido para la mayoría de la ciudadanía. De su reconocimiento depende la reconstrucción de la memoria educativa de cada generación, de nuestras tradiciones y prácticas educativas, teniendo en cuenta que en muchos momentos ha sido manipulada, cuando no silenciada y sesgada. Un tesoro cultural, científico e histórico que no debe quedar al margen de la sociedad.

\section{Webs de interés relacionadas}

$>$ http://asociacioninstitutoshistoricos.com

$>$ www.patrimonioeducativo.es

$>$ institucional.us.es/paginasephe

$>$ www.ceimes.es

$>$ www.museodeciencias.org

$>$ www.aguilaryeslava.org/museo/historia

$>$ www.iescabrerapinto.com/CULTURA/museos.php

$>$ recursostic.educacion.es/var/arce/web

$>$ www.mecd.gob.es/cee/publicaciones/revista-participacioneducativa.html

$>$ http://www.museodelnino.es

$>$ www.museopedagogicodearagon.com 